\title{
Teoría de la justicia transicional y su vigencia en la reparación de niños, niñas y adolescentes víctimas del conflicto armado en Colombia ${ }^{1}$
}

\section{Theory of transitional justice and its validity in the reparation of child and adolescent victims of the armed conflict in Colombia}

DOI: https://doi.org/10.17981/juridcuc.15.1.2019.15

Fecha de Recepción: 09/09/2019. Fecha de Aceptación: 25/09/2019

\author{
Ruth Cristina García Otero \\ Universidad del Sinú- Elías Bechara Zainúm \\ rcgarciao@yahoo.es
}

Para citar este artículo:

García, R. (2019). Teoría de la justicia transicional y su vigencia en la reparación de niños, niñas y adolescentes víctimas del conflicto armado en Colombia. JURÍDICAS CUC, 15(1). 383414. DOI: http://dx.doi.org/10.17981/juridcuc.15.1.2019.15

\section{Resumen}

El presente trabajo tiene como objetivo analizar los componentes de la justicia transicional, desde la perspectiva del derecho a la reparación de los niños, niñas y adolescentes víctimas del conflicto armado en Colombia. Este análisis se efectúa a través del estudio teórico de la justicia transicional, los estándares internacionales de reparación, el marco legal colombiano y las políticas públicas de reparación con enfoque diferencial para el caso de niños, niñas y adolescentes. Concluyendo, como la indemnización, la reparación judicial y simbólica no generan una efectiva e integral reparación para las víctimas de este grupo.

Palabras clave: Enfoque diferencial; justicia transicional; niños, niñas y adolescentes; derecho a la reparación
Abstract

The objective of this paper is to analyze the components of transitional justice from the perspective of the right to reparation for child victims of the armed conflict in Colombia. This analysis is carried out through the theoretical study of transitional justice, international standards of reparation, the Colombian legal framework and public reparation policies with a differential focus for the case of children and adolescents. In conclusion, like compensation, judicial and symbolic reparation do not generate an effective and integral reparation for the victims of this group.

Keywords: children and adolescents; differential approach; right to reparation; transitional justice 


\section{INTRODUCCIÓN}

Esta investigación se centra en mostrar la manera como se está llevando a cabo la reparación de los niños, niñas y adolescentes víctimas del conflicto armado en Colombia, y si estas medidas han sido acordes con las evidentes necesidades de los ellos o, por el contrario, han resultado insuficientes a la hora de otorgarle una efectiva reparación a este importante grupo de víctimas. Por tal razón este trabajo no incluye a los niños reclutados o que conformaban las filas de los grupos armados ilegales al margen de la ley. La premisa de partida para este análisis es que las medidas de reparación resultantes del proceso de justicia y paz y de la ley de víctimas y restitución de tierras, no han sido las adecuadas a la hora de reparar a los niños, niñas y adolescentes -no reclutados por los grupos armados al margen de las ley-víctimas del conflicto armado, puesto que estas no se encuentran diseñadas bajo un enfoque diferencial entre adultos y este tipo de víctimas, sino que se asimilan como un mismo grupo. Si bien se han diseñado políticas por parte del Sistema Nacional de Atención y Reparación Integral a las Víctimas (SNARIV), estas no llegan a todo el universo de víctimas y muchas veces no son aplicadas con el debido enfoque diferencial.

\section{Metodologia}

Esta investigación es de tipo descriptivo observacional aplicada de método deductivo. A partir de un análisis de las medidas de reparación dirigidas a niños, niñas y adolescentes víctimas del conflicto armado en Colombia, y estudio de la teoría de la justicia transicional y su conceptualización jurídica, con el fin de constatar su vigencia y aplicabilidad en el proceso transicional colombiano.

\section{Desarrollo}

\section{Teoría de la Justicia Transicional}

La justicia transicional, como marco teórico y normativo, otorga las herramientas necesarias para analizar de qué forma se pue- 
den llevar a cabo las transiciones en aquellas sociedades que, luego de vivir conflictos armados o dictaduras, buscan dar fin a las situaciones de violencia, por medio de la búsqueda de la paz y/o la democracia sostenible y duradera (Oficina del Alto Comisionado de las Naciones Unidas para los Derechos Humanos, OHCHR, 2005)

La justicia transicional, entendida como:

El conjunto de arreglos judiciales y extrajudiciales que facilitan y permiten la transición de un régimen autoritario a una democracia o de una situación de guerra a una de paz, buscando aclarar la identidad de las víctimas y los destinos de las víctimas y victimarios, estableciendo los hechos relacionados con las violaciones de derechos humanos en situaciones de autoritarismo y/o conflicto armado y diseñando las formas en que una sociedad abordará los crímenes perpetrados y las necesidades de reparación (Rettberg, 2005, p. 2),

Se ha convertido en un concepto utilizado recientemente en el concierto internacional la cual, en realidad, persigue solucionar el antiguo problema sobre qué hacer con las víctimas y los victimarios luego de superado el escenario de violencia, buscando como fin último la reconciliación nacional.

Se pueden diferenciar tres etapas en la evolución del término justicia transicional. La primera fase inicia en el año de 1945 tras el fin de la Segunda Guerra Mundial, una etapa caracterizada por una marcada influencia hacia la política de juicio y castigo por parte de tribunales internacionales como el Tribunal de Nuremberg, en el cual se otorgaron duras penas a los individuos responsables de crímenes contra la humanidad ${ }^{2}$.

Al inicio de la década de los 80 se originó la segunda fase de la justicia en transición, donde se evidenciaron las problemáticas intrínsecas de la política de juicio y castigo, y se propició el comienzo de la política de perdón y olvido, evitando aplicar toda justicia penal para los victimarios lo cual favoreció la justicia restaurativa. Durante este período se vivieron múltiples procesos transicionales, entre los que se destacan las transiciones de las dictaduras a las 
democracias en el Cono Sur, o de la guerra a la paz en Centroamérica; en la mayoría de estas transiciones, el nivel de justicia impuesta a los perpetradores de crímenes contra la humanidad fue mínimo, favoreciendo las amnistías con el fin de lograr una rápida reconciliación nacional.

El segundo período de justicia transicional dio paso a otro concepto esencial en los procesos de transición: la noción de verdad, la cual surge de la necesidad que tiene la sociedad de conocer por qué y cómo ocurrieron los hechos transcurridos durante la etapa de violencia, creándose así las Comisiones de la Verdad, generalmente independientes del Estado, que tienen como objetivo investigar y aclarar los actos violentos cometidos.

En la tercera etapa de la justicia transicional, surtida actualmente, se ha procurado crear un balance entre la justicia para los victimarios, como el derecho a saber y a la reparación de las víctimas. Lo anterior se ha dado en gran parte por la internacionalización de los procesos transicionales, con la creación de estándares internacionales para salvaguardar los Derechos Humanos y el Derecho Internacional Humanitario, así como de entes supranacionales como la Corte Penal Internacional, la cual tiene la facultad de tomar decisiones en los procesos en transición cuando el Estado no cuente con capacidad para ello. No obstante, lograr la reconciliación nacional es una tarea ardua que requiere la voluntad de todas las partes involucradas en el conflicto, no sólo los victimarios y las víctimas, sino también del Estado como ente garante de la efectividad del proceso de transición.

De allí se desprende que los procesos de Justicia Transicional contengan cuatro componentes básicos que se deben garantizar, a saber: 1) la aplicación de la justicia para quienes hayan cometido graves violaciones a los derechos humanos y graves infracciones del derecho internacional humanitario; 2) la búsqueda de la verdad, cuyo propósito es esclarecer los hechos ocurridos en el marco del conflicto; 3) proporcionar una perspectiva histórica de los acontecimientos y 4) rescatar la memoria tanto de las víctimas como de la población civil para garantizar la no repetición de lo ocurrido. 
El tercer elemento, hace referencia a la reparación de las víctimas cuyos derechos se han visto quebrantados por el accionar de los grupos armados violentos.

Del mismo modo es importante mencionar que, dada la responsabilidad del Estado por las acciones cometidas anterior a la transición, es fundamental que el proceso de justicia transicional obligue a los Estados a efectuar una reforma institucional tendiente a fortalecer las falencias en el interior del mismo, que por acción u omisión, posibilitaron las violaciones de los Derechos Humanos y del Derecho Internacional Humanitario, ya que no se debe olvidar que el Estado es el principal garante del ejercicio efectivo de estos derechos, tanto en tiempos de paz como en tiempos de conflicto armado. En este sentido, la consolidación de una efectiva reforma institucional debe ser una salvaguardia para no repetición de factores que ocasionaron la situación violenta.

\section{Derecho a la Justicia}

De acuerdo con Uprimmy y Saffón (2006), es el componente de justicia el que le otorga una connotación novedosa a los procesos de justicia transicional puesto que estos “... se ven regidos por las exigencias jurídicas de justicia impuestas desde el plano internacional, que se concretan en el imperativo de individualizar y castigar a los responsables de crímenes de guerra y de lesa humanidad cometidos en la etapa previa a la transición" (p. 115).

La aplicación de la justicia a aquellos que han cometido violaciones a los Derechos Humanos e infracciones al Derecho Internacional Humanitario es uno de los grandes dilemas que se presenta en los procesos de justicia en transición. En la medida que exista un actor vencedor y uno vencido al momento de iniciar la transición, resulta sencillo aplicar la justicia punitiva a los responsables de los crímenes; pero en aquellos casos en los cuales no es factible concluir que haya un ganador y un perdedor del conflicto, sino que éste se haya solucionado por medio de una negociación, es menor la capacidad que se tiene para poder imponer castigos a los victimarios. 
De acuerdo con lo anterior, el Estado se encuentra en la encrucijada entre imponer penas ejemplares y justas a los perpetradores de crímenes logrando los imperativos de justicia, o en su defecto, favorecer políticas de "perdón y olvido" entre las que se incluyen amnistías o indultos a los victimarios en aras de alcanzar acuerdos que satisfagan a todas las partes de la negociación, y de esa manera lograr la reconciliación nacional. Para ello, los gobiernos, a la hora de decidir los niveles de justicia que van a aplicar en el proceso de transición, cuentan con tres alternativas, como puede observarse en la Tabla 1:

TABLA 1.

Niveles de Justicia

\begin{tabular}{|c|c|}
\hline Nivel de Justicia & Arreglo Institucional \\
\hline Bajo & Amnistías, Indultos o Impunidad \\
\hline Medio & Sanciones no Criminales \\
\hline Alto & Sanciones Criminales \\
\hline
\end{tabular}

Fuente: Goebertus y Maya (2007, p. 8).

Aunque no existe consenso en el nivel de justicia que se debe aplicar para que el proceso de justicia transicional sea exitoso, los principios internacionales sobre la lucha contra la impunidad afirman que es necesario incorporar medidas tendientes a combatir todas las políticas llamadas a favorecer a los victimarios con amnistías e indultos, argumentando que los delitos no deben quedar sin castigo por:

[...] las personas que cometían violaciones de los derechos humanos fuesen civiles o militares, se volvían más descaradas cuando no tenían que rendir cuentas ante un tribunal... la impunidad también podía inducir a las víctimas de estas prácticas a recurrir a alguna forma de autoayuda y a tomarse la justicia por su mano, lo que a su vez exacerbaba la espiral de violencia (Van Boven, 2007, p. 296)

Por ello, durante la transición hacia la paz, el Estado está en la obligación de encontrar una solución política que no promueva 
la impunidad total, pero si abra paso a una especie de impunidad parcial en la cual se imponga el principio de proporcionalidad ${ }^{3}$. En este sentido, en los procesos transicionales se debe evitar que el nivel de justicia exigido sea mínimo, puesto que es contradictorio con las necesidades de las víctimas; pero también es menester procurar que los castigos otorgados a los victimarios no sean iguales a las penas que reciben quienes no se acogen a los beneficios de la justicia de transición.

De esta manera, en los procesos de transición prevalece la justicia política ${ }^{4}$ antes que la justicia legal, la cual permite que el victimario se responsabilice y se arrepienta por su accionar pretransición, y a su vez pueda reincorporarse más fácilmente a la sociedad; y de otra parte, que las víctimas puedan disminuir su dolor y su necesidad de justicia, consiguiendo perdonar a los victimarios por los crímenes cometidos, sin que la imposición de justicia se convierta en la búsqueda de venganza. Sin embargo, debe evitarse que se generen unos pocos culpables y una mayoría víctima (Goebertus y Maya, 2007), haciendo que el crimen se visualice como un acto correcto para la sociedad.

En este sentido, a la hora de responsabilizar a los perpetradores de delitos, el Estado tiene como obligación investigar las violaciones de Derechos Humanos y las infracciones al Derecho Internacional Humanitario de manera eficaz, completa, rápida e imparcial; y posterior a la consecución de las pruebas necesarias, el Estado está en el deber de juzgar y castigar a los que fueran encontrados responsables, pero respetando en el juicio las reglas del debido proceso. A su vez, es menester que, en materia de justicia, el Estado garantice a las víctimas su acceso efectivo a los recursos judiciales que le permitan denunciar y resarcir los daños ocasionados por las violaciones que han sufrido (ONU. ECOSOC, 2005).

Todo lo anterior implica que el Estado determine de forma precisa las reglas con las cuales los victimarios serán perdonados o castigados, dado que esto es requisito prima facie desde que las partes en conflicto consiguieron el acuerdo de paz, que permita superar las experiencias violentas y reconstruir los vínculos y confianza 
entre los miembros de la sociedad y la convivencia, valores que fueron destruidos a lo largo del conflicto en Colombia. En torno a lo anterior, la ONU (2006) argumenta que en todo proceso de justicia es menester tener en cuenta no sólo la legislación nacional sino también las obligaciones jurídicas internacionales, especialmente aquellas contenidas en el Derecho Internacional Humanitario y los Derechos Humanos. Consecuente con este principio, el Estado debe procurar que las normas nacionales siempre sean concordantes con las acordadas internacionalmente y que las violaciones cometidas no se sujeten a términos de prescripción.

\section{Derecho a la Verdad}

Uno de los elementos fundamentales a la hora de adentrarse en un proceso de transición es la búsqueda de la verdad. Como se mencionó anteriormente, el esclarecimiento de los hechos ocurridos es de vital importancia para que las víctimas puedan sanar sus heridas y conceder perdones a sus victimarios, de ahí que la verdad, como lo establece Goebertus y Maya (2007) esté compuesta por "el derecho inalienable a la verdad, el deber de recordar y el derecho de las víctimas a saber" (p. 10).

El conocimiento efectivo de la verdad representa un reto para la justicia transicional, puesto que la sociedad oscila entre concederle mayor importancia a la construcción de la memoria o que prevalezca el olvido en el proceso. Se podría pensar que privilegiar el olvido permite una reconciliación más rápida entre las partes del conflicto, puesto al no darse a conocer los hechos violentos se inhibe el surgimiento de nuevos y mayores rencores al interior de la sociedad; no obstante, los procesos transicionales han evidenciado que el esclarecimiento de estos sucesos posibilita un mayor resarcimiento a las víctimas y ofrece una mayor garantía de que estos hechos no se reiteren (No repetición).

Existen dos dimensiones de verdad en los procesos transicionales: la verdad individual y la verdad colectiva. La verdad individual, tiene un propósito reparador, por medio de la cual se busca que la víctima o sus familiares conozcan por qué ocurrieron las 
violaciones, quien las consumó, cuándo se ejecutaron y, ante todo, en el caso de las desapariciones forzadas, los secuestros y las ejecuciones extrajudiciales, conocer el destino y la suerte de las víctimas o de sus cuerpos. En este sentido, el esclarecimiento de la verdad individual permite la restauración de la dignidad de la víctima y su reintegración a la sociedad. Por su parte, el derecho a la verdad colectiva tiene como fin último la creación de una memoria colectiva, como afirma Uribe (2006):

[...] para los públicos que la escuchan es pedagógica y esclarecedora; para la historia de los pueblos y de las naciones es condición necesaria e irremplazable y para los Estados, los gobiernos y los ciudadanos, una lección sobre lo que no debe volver a ocurrir y sobre la naturaleza de las acciones que deben adoptarse para suprimir las determinaciones de diversa naturaleza que llevaron a tal situación de desgarramiento y horror (p. 328).

De esta manera, la justicia transicional, para ser efectiva, debe cumplir tanto con el esclarecimiento de la verdad individual por medio de procesos judiciales en las cuales se lleven a cabo versiones libres, donde se escuchen los relatos tanto a los victimarios como a las víctimas, sobre los hechos violentos acontecidos y se pueda hacer valer el derecho a la justicia; como con la construcción de la verdad colectiva a través de mecanismos extrajudiciales de investigación, en los cuales prevalecen las Comisiones de la Verdad, que permiten reconstruir la verdad histórica y fortalecer el deber de recordar. Es importante también crear días de conmemoración de las víctimas, monumentos y demás mecanismos simbólicos que permitan que la sociedad no olvide lo ocurrido y construya un pasado compartido, siendo esta la única forma para evitar que los actos violentos vuelvan a acontecer.

\section{Derecho a la Reparación}

Una de las partes más importantes en los procesos de justicia transicional son las víctimas, definidas por la ONU (2006) en la Resolución 2005/35 (ECOSOC, 2005), la cual dispone prin- 
cipios y directrices básicos sobre el derecho de las víctimas de violaciones de las normas internacionales de derechos humanos $\mathrm{y}$ del derecho internacional humanitario a interponer recursos y obtener reparaciones, como:

toda persona que haya sufrido daños, individual o colectivamente, incluidas lesiones físicas o mentales, sufrimiento emocional, pérdidas económicas o menoscabo sustancial de sus derechos fundamentales, como consecuencia de acciones u omisiones que constituyan una violación manifiesta de las normas internacionales de derechos humanos o una violación grave del derecho internacional humanitario...cuando corresponda el término víctimas comprenderá a la familia inmediata o a las personas a cargo de la víctima directa y a las personas que hayan sufrido daños a intervenir para prestar asistencia a víctimas en peligro o para impedir victimización (ONU, 2006, art. 8)

En los modelos de justicia transicional, el Estado, los victimarios y la sociedad en general, tienen un compromiso moral con las víctimas, que se materializa en el derecho a la reparación. Este derecho se ha fortalecido gracias a los movimientos de derechos humanos, quienes han procurado que los procesos transicionales estén centrados en la víctima, su aflicción y sus necesidades.

Acorde con Naciones Unidas, la reparación se centra en el derecho a ser destinatarias de acciones individuales de restitución, indemnización y rehabilitación, de medidas de satisfacción de alcance general y de garantías de no repetición (ONU, 2006). En este sentido, los procesos de justicia en transición deben incluir dos formas de resarcimiento, la individual y la colectiva. Las víctimas deben recibir una adecuada reparación individual que se presenta cuando una persona acude ante un juez, y ese juez condena al responsable de un crimen y obliga indemnizar a la víctima, y es una indemnización individual. Y una segunda indemnización individual es cuando un juez obliga a un actor armado a devolver los bienes expropiados ilegalmente (Comisión Nacional de Reparación y Reconciliación-CNRR, 2000). 
Ahora bien, es indispensable tener en cuenta que restituir completamente a la víctima es una labor ardua, que en ocasiones se vuelve imposible, por existir múltiples situaciones que por su naturaleza no son restituibles, sin olvidar que las víctimas siempre van a sufrir los recuerdos de un pasado violento difícil de olvidar. Sin embargo, es deber del Estado restituir a la víctima en la medida de lo posible, y sólo cuando esto sea imposible, se debe recurrir a la indemnización o compensación. La indemnización comprende el valor económico de los daños sufridos por las víctimas, tanto materiales como morales, que permite que estas superen los efectos de sus pérdidas. En muchos casos resulta factible tasar el valor de los perjuicios sufridos por las víctimas, como son los daños físicos, los daños materiales, que involucran el lucro cesante, los gastos jurídicos, servicios médicos, ayudas psicológicas y sociales a los cuales haya tenido que acudir la víctima en su proceso de reparación. No obstante, los perjuicios morales, los daños mentales y la pérdida de oportunidades, son imposibles de avaluar, por lo cual, la compensación no puede resultar el único mecanismo de reparación.

Indistintamente, la rehabilitación de las víctimas, cuyo objetivo es procurar que éstas superen las secuelas que el conflicto les deja, se basa en el otorgamiento de tratamiento médico, psicológico y jurídico. En este sentido, recomienda que los gobiernos creen paquetes de servicios, en los cuales se incluya la prestación de aquellos servicios como la educación y la salud, que son fundamentales para el pleno desarrollo de todos los ciudadanos, ya que como él mismo argumenta, los programas de reparación deben "... dar reconocimiento a las víctimas, pero no como víctimas sino como ciudadanos con iguales derechos a los demás ciudadanos" (De Greiff, 2006, p. 213).

Adicional a los tres mecanismos de reparación individual es de vital importancia favorecer la reparación colectiva, con la cual se conmemoran a las víctimas por los daños que le fueron infringidos. La reparación colectiva se compone de las medidas de satisfacción caracterizadas por la búsqueda y divulgación de la verdad que 
permiten reestablecer los derechos y la dignidad de las víctimas, la imposición de justicia para los victimarios, acompañada de la disculpa pública a las víctimas, y la realización de homenajes a las víctimas. A su vez, las medidas de reparación colectiva incluyen las garantías de no repetición, donde es labor del Estado lograr un ambiente propicio para prevenir que se originen nuevos conflictos armados procurando erradicar todos los factores detonantes del conflicto.

Sumado a lo anterior, los principios internacionales sobre reparación a las víctimas establecen que las formas de reparación se deben llevar a cabo de manera suficiente, rápida y efectiva. Así mismo, y tal como se ha mencionado reiterativamente, el Estado tiene el deber de garantizar que aquel que haya ocasionado la violación resarza a sus víctimas. En el caso en el cual el victimario no se encuentre en capacidad de cumplir con esta obligación, esta se hace imputable al Estado como garante de los derechos de las víctimas.

De esta manera, el gobierno debe crear mecanismos y fuentes alternativas de reparación, que no sólo se basen en los bienes incautados a los victimarios, sino también a través de un rubro del presupuesto nacional y de la creación un fondo especial para la reparación de las víctimas, que puede incluir donaciones que se realicen a favor de la causa de las víctimas. La efectiva reparación resulta esencial para darle legitimidad y credibilidad al proceso de justicia transicional. No obstante, son pocos los casos en los cuales las medidas de reparación llegan a satisfacer los vacíos de las víctimas y logran una verdadera reconciliación nacional basada en otorgar perdón y olvido.

Por ello, es un compromiso del Estado y de la sociedad civil promulgar que en el proceso de transición la reparación de las víctimas sea integral, que esta no cumpla sólo con los cinco mecanismos de reparación, sino que igualmente tenga en cuenta el papel fundamental de la justicia y la verdad como función reparadora de las víctimas, puesto como afirma De Greiff (2006), adicional a las reparaciones, las víctimas "también necesitan enjuiciamiento 
y confesiones de verdad porque si no se verá más como un intento de comprar el silencio de las víctimas y de sus familias" (p. 216), como una oportunidad de resarcir el pasado y brindar reconciliación y paz al Estado.

\section{Derecho a la Reparación de niños, niñas y adolescentes conforme a los estándares internacionales}

Para los efectos de este estudio, se entiende por niño a "todo ser humano menor de dieciocho años de edad, salvo que, en virtud de la ley que le sea aplicable, haya alcanzado antes la mayoría de edad" (ONU, 1989, art. 1), entendiendo que este concepto cobija entonces a las niñas y adolescentes; y para definir civil se acoge el Principio de Distinción enunciado en el Protocolo I del IV Convenio de Ginebra (ONU, 1949), el cual estipula como civil a toda aquella persona que no participa directa o activamente en las hostilidades durante las guerras.

De acuerdo con la Organización de las Naciones Unidas (2007):

[...] las guerras violan todos los derechos de los niños, el derecho a la vida, el derecho a estar con su familia y comunidad, el derecho a la salud, el derecho al desarrollo de su personalidad, y el derecho a estar protegidos" (p.15).

Ser víctima de alguno de los efectos de la guerra puede generar profundas consecuencias emocionales en los niños, niñas y adolescentes que no entienden la magnitud del conflicto armado; estos traumas se pueden traducir en temor, miedo, dependencia, resignación e incapacidad de proyectarse adecuadamente al futuro. Según Pardos (2002): "La recuperación psicosocial de la infancia afectada por la violencia de una guerra es básica para el desarrollo integral y tolerante de la comunidad" (p. 116). Lo anterior evidencia como sin un adecuado proceso de reparación integral de los niños víctimas de la violencia es poco probable que estos se desarrollen adecuadamente. Es por lo anterior que la protección jurídica de los infantes se ha vuelto fundamental tanto en el Derecho Internacional como en las legislaciones nacionales de los países. De esta 
manera, existen dos marcos normativos en los cuales se establece la protección de los niños, niñas y adolescentes en tiempos de guerra, a saber: el Derecho Internacional Humanitario y el Derecho Internacional de los Derechos Humanos.

En el marco de la Convención de Ginebra de 1949 se aprobaron cuatro Convenios que regulan el Derecho Internacional Humanitario. Entre estos convenios se creó el relativo a la protección debida a las personas civiles en tiempo de guerra (ONU, 1949), por medio del cual se dictaminaron medidas para garantizar la efectiva protección de la sociedad civil, incluyendo a los niños, niñas y adolescentes, en medio del conflicto armado. El artículo 50 de la mencionada Convención (ONU, 1949), dispone que para tiempos de guerra, se debe procurar realizar una correcta identificación y registro de los niños, en especial de los huérfanos, tras el conflicto; así como garantizar proteger su derecho a la educación, a la nutrición y a la asistencia médica.

Esta Convención fue fortalecida en el año de 1977 con el surgimiento de los Protocolos I y Protocolo II adicionales a los Convenios de Ginebra (ONU, 1949b), relativos a la protección de las víctimas de los conflictos armados sin carácter internacional, en los cuales se recogieron normas específicas sobre la protección de los niños. El primero determina que los niños serán objeto de un respeto especial y se les protegerá contra cualquier forma de atentado al pudor y que las Partes en conflicto les proporcionarán los cuidados y la ayuda que necesiten, por su edad o por cualquier otra razón. Mientras que el Protocolo II crea una lista de obligaciones entre las que se incluyen el deber de tener adecuados sistemas de educación y de reunir a las familias al final de la crisis ${ }^{5}$.

En general, y tal como lo señalan los 25 artículos de las Convenciones de Ginebra y de sus protocolos (ONU, 1949) tratan de proteger a la población infantil en situaciones de conflictos armados previendo, por ejemplo, la protección de los niños contra los efectos de las hostilidades asegurando una ayuda humanitaria (víveres y agua, ropa y cobijo) y de sus derechos (dignidad, edu- 
cación, religión, reagrupamiento familiar), la evacuación de las zonas de conflictos, la creación de zonas de seguridad para alejar a los más desfavorecidos, la limitación de medios y métodos de combate, y la prevención en la participación de los niños en los conflictos armados.

A finales de la década de los 80 se adoptó la Convención sobre los Derechos del Niño (ONU, 1989), la cual define el término niño como "todo ser humano menor de dieciocho años, salvo que, en virtud de la ley que le sea aplicable, haya alcanzado antes la mayoría de edad" (art. 1). Es así como esta Convención es un instrumento vinculante para los Estados que lo hayan ratificado ${ }^{6}$, el cual impone obligaciones relacionadas con los derechos humanos básicos que los infantes deben disfrutar en aras de tener un desarrollo adecuado.

En este sentido, la United Nations Children Fund-UNICEF, que fue creada en la década de los 40 con el surgimiento de la ONU, para promover el bienestar a los niños, niñas y adolescentes víctimas de los conflictos armados, ha estipulado que, al ser parte de la Convención, los Estados deben crear programas para asegurar la adecuada prestación de los servicios de salud, educación y demás servicios jurídicos, civiles y sociales. Así mismo, es menester que los Estados parte aseguren, sin discriminación alguna, el derecho de todos los a la vida, al desarrollo, a la protección contra influencias peligrosas, a los malos tratos, a la explotación, y a la plena participación en la vida familiar, cultural y social (ONU, 1989).

De acuerdo con lo anteriormente expuesto, se puede señalar como la justicia transicional es un tipo especial de justicia que se implementa cuando, en medio de un conflicto armado o de una dictadura, el Estado en aras de ponerle fin a la situación de violencia e inestabilidad y por ende de lograr la paz y/o la democracia, propone medidas especiales tanto para los victimarios como para las víctimas durante la transición. Teóricamente, los procesos de justicia en transición deben incluir tres derechos: El derecho a la justicia, el derecho a la verdad y el derecho a la reparación. Sin embargo, 
cada transición se lleva a cabo de forma diferente, teniendo como referente las realidades y necesidades propias del país en conflicto. Por ello, en la práctica no todos los procesos transicionales tienen el mismo grado de verdad, justicia y reparación; sino que se priorizan unos sobre los otros, de acuerdo con la naturaleza del conflicto, las condiciones de negociación, la fortaleza institucional y la cultura democrática en que se inscribe.

De tal manear que el derecho a la reparación de las víctimas tiene como finalidad indemnizar, restituir, rehabilitar, y satisfacer a las víctimas y a sus familiares, así como garantizarles que los hechos ocurridos no se repetirán. La reparación es elemento fundamental en los procesos de transición, puesto que es el que mayor relevancia se les da a las víctimas que son quienes sufrieron las consecuencias del conflicto.

Reparación de los niños, niñas y adolescentes en el marco normativo colombiano

La principal víctima de los conflictos violentos es la sociedad civil, que, sin estar directamente involucrada en la confrontación armada, resulta altamente perjudicada por los enfrentamientos entre las partes combatientes. Tal como lo manifestó en su momento el Informe de la experta del Secretario General, Graça Machel (1996):

[...] en los últimos decenios la proporción de víctimas de guerra entre los civiles ha aumentado notablemente, de un $5 \%$ a más del $90 \%$. Los combates que cobran más vidas civiles que soldados han estado marcados por niveles horribles de violencia y brutalidad (1996, p. 9).

Dentro de la población civil afectada por los estragos de la guerra existen grupos que, por su etnia, condición de capacidad especial física o de salud mental, género, raza y/o edad, presentan mayor vulnerabilidad a los conflictos armados; en este sentido, la niñez es uno de los grupos poblacionales que sufre en mayor proporción los efectos adversos de la guerra ya que ésta lesiona 
todos los derechos de la infancia, impidiéndoles disfrutar de los servicios de salud, educación, del juego y la recreación, la adecuada alimentación y de la protección del núcleo familiar, entre otras violaciones y que sin duda repercuten en el resto de su vida personal, familiar y laboral y esto necesariamente afecta a la comunidad en la que se desarrolla, y este es el caso de niños y también de aquellos que hoy ya son adultos y que fueron víctimas del conflicto armado y no recibieron servicios sicosociales.

Es así como, el impacto negativo que los conflictos armados pueden generar en la niñez deja secuelas que repercuten en el desarrollo del menor, perjudicando su bienestar tanto en el presente como en el futuro. Tal como lo afirma el citado informe:

[...] muchos de los conflictos de la actualidad duran durante toda la 'infancia', lo que significa que desde el nacimiento hasta el principio de la edad adulta los niños experimentarán múltiples agresiones que se irán acumulando. El resquebrajamiento de la red social y de las relaciones primarias que sirven de apoyo al desarrollo físico, emocional, moral, cognoscitivo y social de los niños durante tanto tiempo puede tener consecuencias físicas y psicológicas profundas (Machel, 1996 p. 16).

La niñez se victimiza por los conflictos armados, mientras que otros se ven afectados de forma indirecta. Los niños que sufren las consecuencias del conflicto de forma indirecta pueden sentir temor e inseguridad al pensar que en algún momento la situación violenta pueda repercutir en ellos o en sus familias.

Otra de las repercusiones para los niños, y adolescentes víctimas del conflicto armado, son el desplazamiento forzado ya sea al interior del Estado o hacia otros países como refugiados; la violencia y explotación sexual; el secuestro y la desaparición forzosa; la falta de acceso a los servicios de salud, educación y las ayudas humanitarias; la mutilación de uno o varios de sus órganos; y la propia muerte, generando como se ha señalado consecuencias terribles en su condición de seres humanos (Muñoz, 2015).

En recientes datos: 
Colombia ocupa el tercer puesto, entre 175 países, con la tasa más alta de homicidio infantil en el mundo, según el último informe de la organización internacional no gubernamental Save the Children, que estudió datos entre el 2015 y el 2017. Tan solo hay que ver que el año pasado fueron asesinados 715 menores (de 0 a 18 años) en el país (Granja, 2018, p. 1).

La Ley de Justicia y Paz (Ley 975, 2005), garantizando los derechos de las víctimas a la verdadera justicia y reparación (Comisión Colombiana de Juristas, 2007) es pobre al no contener más que simples enunciados sobre la protección y atención que estos deben recibir. En este sentido, la "Protección a víctimas y testigos" (art. 38), la "Expresión a la publicidad en el juicio" (art. 39) y la "Atención a necesidades especiales" (art. 41), establecen que se deberán adoptar todas medidas que aseguren el bienestar físico, psicológico, la dignidad, la seguridad y la vida privada de las víctimas y testigos, teniendo en cuenta factores tales como la edad de estos. A su vez expone (Ley 975, 2005), en situaciones como la violencia sexual, el irrespeto a la igualdad de género o la violencia contra niños y niñas resulta menester tener en cuenta las necesidades especiales de las víctimas de estos delitos en el transcurso del proceso; cuando los niños sean víctimas o testigos de este tipo de acciones podrán realizar sus testimonios por video. A pesar de estos enunciados, la ley no contiene artículos específicos sobre la especial reparación que se debe otorgar a los niños, niñas y adolescentes víctimas del conflicto armado y tampoco trata las formas como el proceso reparatorio de los infantes se debe llevar a cabo.

La Ley de Víctimas y Restitución de Tierras (Ley 1448, 2011), trata de llenar este vacío, por lo cual se transcriben los artículos donde se resalta la condición de niño y niña y se establece un tratamiento especial en sus artículos, 3, 13, 38, 136, 149, 176 y del 182 al 185, por tal razón se puede afirmar que la Ley de Justicia y Paz (Ley 975, 2005) y la Ley de Víctimas y Restitución de Tierras (Ley 1448, 2011) constituyen un esfuerzo del gobierno por seguir los lineamientos internacionales sobre los derechos a la verdad, 
la justicia y la reparación que tienen las víctimas de un conflicto armado en todo proceso de justicia transicional.

En el país son pocas las víctimas que recibirán una reparación integral por parte de los desmovilizados o, en su defecto del Estado. El gobierno ha primado la reducción de penas a los miembros de los grupos desmovilizados, con el fin que estas no vuelvan a enlistarse, dejando a un lado la búsqueda de la verdad y la reparación integral de las víctimas; sin tener en cuenta que, en todo proceso de justicia transicional, es menester darle prioridad a los derechos que tienen las víctimas ya que estas fueron a las que mayores sufrimientos les generó el conflicto. Si esto no sucede, no es posible hablar de una efectiva transición, de perdón, de olvido y muchos menos de reconciliación nacional, porque las víctimas siempre sentirán que su dolor y sufrimiento fue poco importante para el gobierno y la sociedad en general (González, 2014).

En este sentido, Botero y Restrepo (2006) argumentan:

En Colombia, las víctimas de vulneraciones graves de los derechos humanos o del derecho internacional humanitario que estimen que sus derechos a la verdad, la justicia y la reparación han sido conculcados por las autoridades pueden recurrir a varios mecanismos de protección judicial que ofrecen tanto la justicia constitucional como la justicia ordinaria (p. 67).

En Colombia, el principal marco normativo en el cual se establecen los derechos fundamentales de los ciudadanos se encuentra contenido en la Constitución Política (1991). Aunque en la jerarquía de la normativa colombiana, las leyes y los decretos reglamentarios son de obligatorio cumplimiento, es la Constitución la "primera norma" y, por ello, lo estipulado en la misma prevalece por encima de lo dispuesto en las demás normas jurídicas.

A través del Bloque Constitucional se procura que la normativa colombiana recoja lo establecido en el Derecho Internacional, tal y como lo plantea Fajardo (2007), "garantizando la coherencia de la legislación interna con los compromisos ad extra del Estado y al mismo tiempo, servir de complemento para la garantía de los 
Derechos Humanos y el Derecho Internacional Humanitario en el país" (p. 1).

En este sentido, la legislación colombiana ha tipificado los delitos contra la niñez y promulgado una serie de normas para regular la protección infantil en el país. De esta forma, han quedado tipificados como delitos en Colombia, la explotación sexual comercial infantil; el secuestro y la desaparición forzada; la venta, trata y tráfico de menores, el desplazamiento forzado, la colocación de minas antipersonales; la tortura y demás penas crueles a las que puedan ser sometidos los infantes en tiempos de guerra (Instituto Colombiano de Bienestar Familiar-ICBF, 2007).

\section{Reparación por vía administrativa}

La reparación por vía administrativa es aquella por medio de la cual las víctimas del conflicto armado reciben una indemnización de carácter económico; la debe solicitar directamente la víctima de manera voluntaria ante las entidades que el Estado le ha dado potestad para ello, y el Comité de Reparaciones Administrativas es el encargado de decidir si el solicitante es apto para recibir la reparación o no. Para ello, el Comité cuenta con 18 meses para tomar la decisión sobre el monto que podrá recibir la víctima.

El monto máximo al que pueden acceder las víctimas por medio de la vía administrativa es de cuarenta salarios mínimos legales mensuales, de acuerdo con los delitos de los cuales se haya sido víctima e independiente de la cantidad de delitos por los cuales se haya visto perjudicado, que deberá ser otorgado a las víctimas anualmente, en un plazo no mayor a los diez años.

Generalmente, los niños, niñas y adolescentes que han sido víctimas del conflicto armado en el país no acuden directamente a realizar su solicitud de reparación administrativa ya que son sus padres quienes lo hacen por ellos y quienes reciben la suma otorgada por la reparación. Sin embargo, resulta fundamental facilitarles a los niños que perdieron sus padres en el conflicto un representante legal con las facultades para realizar la solicitud de reparación. 


\section{Reparación por vía judicial}

Las víctimas que deseen iniciar su proceso de reparación por la vía judicial deben presentar su solicitud ante cualquiera de las entidades que conforman el Ministerio Público conformada por la Procuraduría Judicial para la Justicia y la Paz y la Defensoría Pública, y asistir a la Audiencia Pública de Reparación con el fin de identificar a su victimario e inculparlo por los perjuicios que le ocasionó y solicitar la reparación que considera. En el momento de la acusación, es fundamental que la víctima presente pruebas suficientes que permitan fortalecer el proceso. Luego, a través de un proceso de conciliación el victimario y la víctima pueden llegar a un acuerdo sobre la reparación solicitada por esta última, y en caso de no estar de acuerdo, el tribunal encargado del proceso debe definir las obligaciones que el victimario debe asumir en pro de la reparación económica y moral de sus víctimas.

Las múltiples dificultades que representa para las víctimas la solicitud de la reparación por la vía judicial, dada la complejidad del proceso en el cual las víctimas deben acudir a múltiples instituciones, cada una de ellas con una responsabilidad diferente ante la reparación de las víctimas, sumado a las altas exigencias en materia de presentación de pruebas y los tecnicismos judiciales manejados en este tipo de procesos, hacen que la víctima prefiera no iniciar un proceso judicial contra su victimario y decida solamente hacer valer su derecho a recibir reparación por la vía administrativa, a pesar que todas las víctimas tienen derecho a la doble reparación.

Reparación en el marco de la ley de víctimas y restitución de tierras

Son víctimas los niños, niñas y adolescentes huérfanos, tanto de madre como de padre, o solo uno de ellos, como consecuencia de las violaciones a las que se refiere la Ley de Víctimas y Restitución de Tierras (Ley 1448, 2011, art. 3). Igualmente, cuando han sido víctimas de minas antipersonales, municiones sin explotar y artefactos explosivos improvisados. De la misma manera, los niños, 
niñas y adolescentes víctima del reclutamiento ilícito. También son considerados víctimas, los niños concebidos como consecuencia de una violación sexual con ocasión del conflicto armado. Por consiguiente, sí tienen derecho a la reparación integral, que incluyen las medidas de indemnización, rehabilitación, satisfacción, restitución y garantías de no repetición. Al restablecimiento de sus derechos y a obtener una indemnización. Los padres o el defensor de familia podrán elevar la solicitud, como representantes legales de los niños, niñas y adolescentes, de la indemnización a la que estos tengan derecho.

Sin embargo, esto es lo que se plantea en la ley, los procedimientos y trámites, pero:

La aparición de elementos no contemplados en el desarrollo de la legislación, la política y los programas abocados a la restitución de tierras ha encontrado, además de la inexistencia de la estructura jurídica propia para resolver este tipo de casos, la presencia de una serie de aspectos y agentes que han desdeñado las virtudes de la restitución desde distintos flancos, llegando incluso al despropósito, lo que puede pervertir en el tiempo una disposición que para muchos puede convertirse en una reforma agraria o que puede entorpecer el curso de actividades o intereses instalados en los predios comprometidos en el proceso. La circunstancia es tal, que el propio Estado ha asumido la gestión de la reclamación de manera directa, precisamente por los vicios que han aparecido en distintos aspectos (Gutiérrez, 2014, p. 159)

\section{Reparación de niños en el marco del instituto colombiano de bienestar familiar}

Este instituto, no tiene, en estricto sentido, la obligación de reparar, sino que cumple la función de prevenir, garantizar y restablecer los derechos, procurando promover su recuperación y habilitación psicológica y social, así como, su reintegración a la sociedad. Para cumplir su función ha implementado una serie de programas, que van dirigidos principalmente para la reintegración de los niños, niñas y adolescentes soldados y no para los niños civiles víctimas. 
Luego de lo anterior expuesto, se observa que el gobierno ha aunado esfuerzos para crear estructuras y procedimientos que garanticen la reparación de los niños, niñas y adolescentes víctimas, no obstante, la inversión en cuidados sicosociales ha sido prácticamente nula, como bien lo plantea Ortegón referido a las mujeres accedidas carnalmente víctimas del conflicto en los Montes de María, municipio de Ovejas (Sucre):

Colombia ha desarrollado descripciones robustas que detallan la tragedia de la guerra, sin embargo, la producción en cuanto al trabajo social dirigido a la reparación y el acompañamiento psicosocial, con un criterio innovador o vinculante frente a los daños psicológicos y emocionales que causó el conflicto armado; es más bien escasa. Son muchos los avances en términos de la política pública, pero muy poco el alcance e impacto en el terreno de lo psicosocial, pese a que los daños son profundos y de dimensiones aplastantes: daños emocionales y psicológicos, rupturas familiares, sociales, pérdidas humanas que significan pérdidas de afectos, de hijos, de padres, de apoyos, de identidades, de ritos y de sentidos. La reparación psicosocial es una gran deuda que tiene el País, la política, la academia y la sociedad en su conjunto con las víctimas que, para el caso específico de este trabajo, son las mujeres víctimas de violencia sexual en el marco del conflicto armado en la región de los Montes de María del departamento de Sucre en Colombia. Este artículo tiene como objetivo, presentar los resultados parciales de investigación frente a la exploración e implementación de un enfoque de abordaje y acompañamiento psicosocial a mujeres víctimas de violencia sexual en el marco del conflicto armado, acudiendo a conceptos como cuerpo y memoria. E indagando en metodologías denominadas no convencionales desde lenguajes simbólicos. Los resultados de la investigación apuntan a que las afectaciones en el cuerpo, ocasionados por el tipo de violencia ejercida hacia las mujeres, causan enfermedad mental y traumatismos diversos a nivel individual y colectivo; pero a su vez, el cuerpo de manera interdependiente, se constituye no sólo en objeto de ataque, sino en campo metodológico, acudiendo a lenguajes expresivos, para restituir memoria, reparar y sanar, "hablando", simbólicamente, de lo que fue silenciado a través del ataque al cuerpo mismo. 
Este trabajo es pertinente dentro del campo del Trabajo Social, en un ámbito multidisciplinario en tanto dialoga con la Antropología y la Psicología buscando en interacción directa con organizaciones de mujeres víctimas del conflicto armado, caminos de reparación psicosocial (Ortegón, 2017, p. 67)

\section{Conclusiones y Recomendaciones}

La reparación se puede entender en dos sentidos: desde la interpretación jurídica donde los incidentes de reparación son vistos como un fin que tiende a restringir la voz de la víctima; y desde una lectura psicosocial que ve la reparación como un fin pero también es un proceso que debe ser reparador y no vulnerante, en donde la relación con la víctima no debe ser utilitaria y en el cual todo momento debe ser cuidadoso porque sólo así la víctima va a sentir que efectivamente fue reparada. Por ello la indemnización, la reparación judicial y la reparación simbólica, que son aquellos temas que han prevalecido en los procesos de reparación en Colombia, no tienen un efecto reparador integral en las víctimas.

Los niños, niñas y adolescentes víctima, merecen especial atención cuando están inmersos en situaciones de conflicto armado dado que en esa etapa de la vida el ser humano está construyendo identidades ya sean individuales, colectivas o comunitarias por lo que, si en su diario vivir deben enfrentarse con ambientes violentos, tenderán a replicar las formas organizativas que la violencia y el conflicto han dejado en ellos como imaginario único, es decir como su única verdad conocida. Por ello, es posible afirmar que el principal efecto psicosocial que tiene el conflicto en los niños se evidencia en el tema educativo, traducido en la manera como ellos crecen y lo que terminan creyendo; situación que es más visible en un conflicto como el colombiano donde la violencia ha sido histórica, por lo cual hay efectos del conflicto inherentes en las estaciones más íntimas de las personas pero que también están presentes en las interacciones diarias de la sociedad. 
Para poder tratar la reparación como un proceso, es importante crear espacios donde los niños puedan contar sus experiencias como víctimas. Estos siempre van a tener relatos dominantes y lecturas de sí mismos que terminan alentando creencias que los van a llevar a tener emociones de rabia y de dolor, que van a reflejar esos sentimientos. Sin embargo, es importante darle un lugar y un reconocimiento a ese dolor, en lugar de tratar de cambiarlo, porque en una historia de vida el dolor es válido y normal, más aún cuando la situación por la que atravesó el infante es anormal.

Por ello, el tratamiento, no debe buscar cambiar las creencias de los niños, niñas, y adolescentes sino abrir relatos alternos o relatos subterráneos, es decir, historias en la que ellos se vean a sí mismos de una forma distinta y que no están ligadas a los momentos de dolor. La reparación de un niño violentado no puede estar orientada al olvido, sino que debe ayudarle a entender la situación que le pasó, a vivir con su historia y darle un significado a la misma (García, Burbano y Córdova, 2018, p. 108)

De esta manera, para llevar a cabo una efectiva reparación no sólo se debe tener en cuenta la reparación administrativa ya que esta se debe complementar los otros tipos de reparación, es decir, la rehabilitación, la restitución, la satisfacción y las garantías de no repetición. En relación con estas últimas, es fundamental cambiar la situación de derechos, para que el niño más adelante se reconozca a sí mismo como un sujeto que sepa cómo exigir sus derechos. Así mismo, es necesario cambiar la situación de violencia, ya que es imposible llevar a cabo procesos de reparación si continúan los efectos que crearon el problema y en niño sigue inmerso en la misma situación de violencia. Con ello lo único que se está haciendo es generar niños disociados de su realidad con lo que realmente es su diario vivir.

De acuerdo con lo anterior, es fundamental que el gobierno nacional, coloque en la agenda pública, la creación de un efectivo programa de reparación para niños civiles que han sido víctimas 
del conflicto armado. Esta política de largo plazo debe tener con fin último la reintegración social de estas víctimas a través del restablecimiento de sus derechos básicos como ciudadanos y niños del país. La política debe contar inicialmente con tres objetivos fundamentales: 1) Orientar esfuerzos hacia la creación y consolidación de una política de largo plazo y diferenciada que articule los problemas que genera la violencia en los niños colombianos, 2) fortalecer la labor de las instituciones que se encargan de la atención de infantes civiles víctimas del conflicto armado colombiano y 3) articular las diferentes medidas reparatorias para que sean un complemento entre sí.

Las estrategias de la política, deben: Crear un sistema que defina la forma de contabilizar los grupos de niños, niñas y adolescentes víctimas, por efecto causado, para que todos ingresen al programa de reparación, realizar talleres con expertos que les permitan a través de medios como la pintura, expresar sus emociones sobre los acontecimientos vividos durante la situación violenta y sus necesidades en el proceso transicional, redactar una cartilla lúdica que les permita entender el proceso de transición y sus derechos durante y después del mismo, proveer la asistencia a la escuela primaria y secundaria. Esto permitiría no sólo incrementar el nivel de educación de este segmento de la población, sino que también evitaría el trabajo infantil y en cierta medida el alistamiento a grupos armados. Asimismo, proveer, a través del Instituto Colombiano de Bienestar Familiar, acceso a la asistencia médica y psicológica, de por vida, para este segmento de víctimas, proporcionar como una ayuda de emergencia través de las escuelas, el desayuno y un almuerzo cada día para los niños, realizar talleres y conversatorios de acompañamiento, para transformar la situación emocional del menor y que de estas experiencias fluyan nuevas narrativas y formas de identidad alternativas al conflicto, llevar a cabo talleres de acompañamiento a familiares, maestros, y a funcionarios públicos, con el fin de cambiar los imaginarios que estos tienen a lo hora de atender a las víctimas, otorgar al menor, a través de un apoderado, una 
suma mensual de dinero que sea utilizada exclusivamente para sus gastos personales. Igualmente, es necesario que, a través de una cuenta bancaria, se le consigne al menor una mensualidad para estudios de Educación Superior. También esta política debe generar mecanismos de desarrollo comunitario que permitan, a largo plazo, la reintegración social de las zonas más afectadas por la violencia en el país.

Tenido en cuenta lo anterior se plantean recomendaciones para la implementación de la política, tales como: incrementar por parte del gobierno nacional y local la cooperación con los demás organismos e instituciones que trabajan en el tema de violencia infantil como UNICEF, para lograr alcanzar las metas propuestas, el gobierno debe coordinar encuentros con el gobierno local, organizaciones no gubernamentales y demás instituciones que se encuentren trabajando en el tema, con el fin de compartir las prácticas implementadas y colaborar con la ejecución efectiva de la política y finalmente es fundamental aumentar el presupuesto nacional y local dirigido a este segmento de la población y crear un rubro especial del Fondo de Reparación para optimizar las estrategias de la política.

\section{REFERENCIAS}

Botero, C. y Restrepo, E. (2006). Estándares Internacionales y Procesos de Transición en Colombia. En, R. Uprimmy, M. Saffon, C. Botero y E. Restrepo, ¿jJusticia transicional sin transición? Verdad, justicia y reparación para Colombia (pp. 45-107.). Bogotá, D.C.: Centro de Estudios de Derecho, Justicia y Sociedad.

Comisión Colombiana de Juristas. (2007). Anotaciones sobre la Ley de Justicia y Paz: Una Mirada desde los Derechos de las Victimas. Bogotá, D.C.: Opciones Gráficas Editores Ltda.

CNR. (2000). Clases de reparación. Bogotá, D.C.: Comisión Nacional de Reparación y Reconciliación. 
De Greiff, P. (2006). Enfrentar el pasado: reparaciones por abusos graves a los derechos humanos. En, C. de Gamboa (comp.), Justicia Transicional: Teoría y Praxis (pp. 204241). Bogotá, D.C.:. Editorial Universidad del Rosario.

Fajardo, L. (2007). Contenido y alcance jurisprudencial del bloque de constitucionalidad de Colombia. Civilizar, 7(13), 15-34. https://doi.org/10.22518/16578953.761

García, R., Burbano N. y Córdova E. (2018). Justicia transicional y la reparación de niños, niñas y adolescentes víctimas del conflicto armado en Colombia. Montería: Unisinú.

Goebertus, J. y Maya, M. (2007). Desplazados sin Tierras ¿Justicia Transicional sin restitución? [Tesis de Grado]. Bogotá, D.C.: Universidad de los Andes.

González, C. (2014). Ley 975 de 2005: Ocho años después, ni justicia, ni paz. Indepaz. [Online]. Recuperado de http://www. indepaz.org.co/wp-content/uploads/2014/02/LEY-975veredicto.pdf

Granja, S. (junio 1, 2018). Colombia es el tercer país del mundo donde se matan más niños. El Tiempo. [Online]. Recuperado de https://www.eltiempo.com/vida/educacion/cifrade-ninos-asesinados-en-colombia-225124

Gutiérrez, J. (2014). Costos sociales de transacción de la Ley de Restitución de Tierras en Colombia: Un país sin Reforma Agraria. Jurídicas CUC, 10(1), 157-196.

Machel, G. (1996). Repercusiones de los conflictos armados sobre los niños. [A/51/306]. Nueva York: ONU. Recuperado de https://www.acnur.org/fileadmin/Documentos/ BDL/2008/6260.pdf

Muñoz, G. (2015). Conflicto Armado en Colombia y sus consecuencias sobre niños y jóvenes. Deseidades, 3(8), 30-39. Disponible en http://pepsic.bvsalud.org/pdf/desi/v8/es_ n8a04.pdf

ONU. (2007). Gewalt gegen KinderKonflikte lösen - Gewalt verhindern. [Online]. Available from: http://www.violencestudy.org/IMG/pdf/English.pdf 
ONU. (2006). Principios y directrices básicos sobre el derecho de las víctimas de violaciones manifiestas de las normas internacionales de derechos humanos y de violaciones graves del derecho internacional humanitario a interponer recursos y obtener reparaciones. [Resolución A/ RES/60/147]. Recuperado de https://undocs.org/es/A/ $\mathrm{RES} / 60 / 147$

ONU. ECOSOC. (2005). Examen de mitad de período del funcionamiento de la estructura de conferencias de la Conferencia de las Naciones Unidas sobre Comercio y Desarrollo Comisión para Asia y el Pacífico. [Resolución 2005/35]. Recuperado de https://www.un.org/ecosoc/sites/www.un.org. ecosoc/files/documents/2005/resolution-2005-35.pdf

ONU. OHCHR. (2005). Pronunciamiento sobre Verdad, Justicia y Reparación en la Audiencia Pública convocada por el Senado de la Republica. [Online]. Recuperado de https:// search.ohchr.org/default.aspx

ONU. (1989). Convención sobre los Derechos del Niño, 1946-2006. Madrid: UNICEF. Recuperado de https://www.un.org/es/ events/childrenday/pdf/derechos.pdf

ONU. (1949). Los Convenios de Ginebra de 1949 y sus Protocolos adicionales. [Online]. Recuperado de https://www.icrc. org/es/document/los-convenios-de-ginebra-de-1949-y-susprotocolos-adicionales

ONU. (1949a). IV Convenio de Ginebra relativo a la protección debida a las personas civiles en tiempo de guerra. [Online]. Recuperado de https://www.icrc.org/es/doc/resources/ documents/treaty/treaty-gc-4-5tdkyk.htm

ONU. (1949b). Protocolo Adicional a los Convenios de Ginebra del elativo a la Protección de las Víctimas de los Conflictos Armados Internacionales (Protocolo I). [Online]. Recuperado de https://www.icrc.org/es/document/protocolo-iadicional-convenios-ginebra-1949-proteccion-victimasconflictos-armados-internacionales-1977 
Ortegón, T. (2017). Cuerpo, memoria y trabajo social abajo social abajo social. Acompañamiento psicosocial con mujeres víctimas de violencia sexual en el marco del conflicto armado en los Montes de María, Sucre, Colombia. Revista regional de trabajo social, 31(70), 66-75

Pardos, L. (2002). Actividades de ocio como factor de reparación psicosocial con niños/as víctimas de la guerra: experiencia en Guatemala. En, M. García y A. Madariaga (comp.), Ocio para todos. Reflexiones y Experiencias. Documentos de Estudio de Ocio. No. 24. (pp. 115-124.). Bilbao: Universidad de Deusto.

República de Colombia. Asamblea Nacional Constituyente. (1991). Constitución Política de Colombia. Gaceta Constitucional, 1(116). Recuperado de http://babel.banrepcultural. org/cdm/compoundobject/collection/p17054coll26/id/3850/ show $/ 3743 / \mathrm{rec} / 8$

República de Colombia. Congreso de la República. (10 de junio de 2011). Ley de Víctimas y Restitución de Tierras. [Ley 1448]. Diario Oficial: 48.096.

República de Colombia. Congreso de la República. (25 de julio de 2005). Ley de Justicia y Paz. [Ley 975]. DO; 45.980.

República de Colombia. Congreso de la República. (22 de enero de 1991). Convencion internacional sobre los derechos del niño. [Ley 12]. DO: 39.640.

República de Colombia. Departamento para la Prosperidad Social. ICBF. (2007). Vinculación a programas de atención especializada para el restablecimiento de derechos vulnerados. [Online]. Recuperado de http://www.icbf.gov. co/Ley_infancia/documentos/Lineamientos\%20Atencion\%20Especializada\%20a\%20victimas\%20de\%20delitos\%20Marzo\%2012.doc

Rettberg, A. (2005). Reflexiones introductorias sobre la relación entre construcción de paz y justicia transicional. En, A. Rettberg (comp.), Entre el Perdón y el Paredón: Preguntas y dilemas de la justicia transicional. Bogotá, D.C.: Uniandes. 
Uprimmy, R. y Saffon, M. (2006). Justicia Transicional y Justicia Restaurativa: Tensiones y Complementariedades. En, R. Uprimmy, M. Saffon, C. Botero y E. Restrepo, ¿̇Justicia transicional sin transición? Verdad, justicia y reparación para Colombia (pp. 109-137). Bogotá, D.C.: Centro de Estudios de Derecho, Justicia y Sociedad.

Uribe, M. (2006). Esclarecimiento histórico y verdad jurídica: notas introductorias sobre los usos de la Verdad. En, C. de Gamboa (comp.), Justicia Transicional: Teoría y Praxis. (pp. 324-344). Bogotá, D.C.. Editorial Universidad del Rosario.

Van Boven, T. (2007). Estudio Relativo al Derecho de Restitución, Indemnización, y Rehabilitación a las víctimas de violaciones flagrantes de los Derechos Humanos y las Libertades fundamentales. En, Comisión Colombiana de Juristas (comp.), Principios Internacionales sobre Impunidad y Reparaciones (pp. 231-306). Bogotá, D.C.: Comisión Colombiana de Juristas.

Ruth Cristina García Otero es abogada de la Universidad del Norte (Colombia) con magíster en Asuntos Internacionales de la Universidad Externado de Colombia y actualmente candidata a doctor en Ciencias Jurídicas de la Pontifica Universidad Católica (Argentina). Docente Investigadora del Programa de Derecho de la Universidad del Sinú (Montería, Colombia). https://scholar.google. es/citations?user=WDdIff8AAAAJ\&hl=es https://orcid.org/00000002-3127-1183 
${ }^{1}$ Este artículo es producto del proyecto de investigación "Justicia transicional y reparación de niños, niñas y adolescentes víctimas del conflicto armado en Colombia" que tributa a la línea de investigación "las dinámicas del derecho en el sistema mundo" del grupo de investigación CINJUN de la Universidad del Sinú- Elías Bechara Zainúm, Montería (Colombia).

${ }^{2}$ La justicia restaurativa hace referencia en la importancia de mirar hacia el futuro y dejar a un lado el pasado de violencia. Este tipo de justicia promulga por la reconciliación nacional propiciando que se den los perdones entre víctimas y victimarios. Este concepto considera que es más importante reparar a la víctima que castigar al victimario ya que a este último lo fundamental es volver a reincorporarlo a la sociedad. La justicia restaurativa es contradictoria con los principios de justicia retributiva en la cual se considera que la imposición de penas y castigos es primordial para lograr un efectivo proceso de transición.

${ }^{3}$ De acuerdo con la Teoría de Proporcionalidad, promovida por Uprimmy y Saffón (2006), el otorgamiento de perdones debe darse de manera excepcional e individual; así como la adjudicación de la pena que debe ser proporcional al papel desempeñado por el victimario en el grupo armado.

${ }^{4}$ La Justicia Política se da cuando se flexibilizan los imperativos de las normas jurídicas, para crear alternativas al Derecho que favorecen el bien común y la convivencia de los ciudadanos.

${ }^{5}$ Colombia ratificó los Convenios de Ginebra el 12 de octubre de 1950, y sus dos (2) protocolos adicionales el 24 de abril de 1991.

${ }^{6}$ Colombia ratificó la Convención sobre los Derechos del Niño mediante la Ley del 12 (1991). 